\title{
Drugs and Society: A Public Health Issue and the New Approaches in Portugal and Uruguay
}

\author{
Ivonaldo Leite \\ Sociologist; $\mathrm{PhD}$ \\ University of Porto, Portugal \\ Professor at the Federal University of Paraíba, Brazil
}

\begin{abstract}
This paper aims to present a general perspective on the relationship between drugs and society, and, at the same time, to develop an analysis of the decriminalization of drugs in Portugal, as well as of the regulated cannabis market in Uruguay. So, methodologically, it is based on both a review of the literature about that subject and an investigation of the primary sources of the Portuguese and Uruguayan drug policy. Among the results found out, it can be highlighting the following sample: 1) the prohibitionist policy on drugs is one of the cases that most reveals ambivalence when it is considered the production of social rules; 2) the so-called drug problem is not and never has been a police problem, except in the sense that the police are themselves the problem - it is, rather, a problem of lack of knowledge and wrong policy approach; 3) the prohibitionist drug policies have failed; 4) Portugal is an example of a well-implemented drug decriminalization policy; 5) the philosophy of Uruguayan drug policy assumes that human rights obligations take precedence over drug control efforts. Conclusively, it is advocated, for example, the implementation of policies that regulate illicit drugs, from production through to distribution.
\end{abstract}

Keywords: Society, drug, public health, Portuguese drug policy, Uruguayan regulation of cannabis

\section{Introduction}

The society is full of things, substances, objects, which we categorize in a variety of ways. In this way, the social groups make rules and attempt, at sometimes and under some circumstances, to enforce them. Social rules define situations and the kinds of behavior appropriate to them, specifying some actions as "right" and forbidding others as "wrong" (Becker, 1963, 1972).

So, when a rule is enforced, the person who is supposed to have broken it may be seen as a special kind of person, one who cannot be trusted to live by the rules agreed on by the "society". This person is regarded as an outsider. But, who can, in fact, force others to accept their rules and what are the causes of their success? This is a question of power, both in its political, economic and cultural dimensions.

Differences in the ability to make rules and apply to other people are essentially power differentials. The groups whose social position gives them weapons and power are best able to enforce their rules. For example, "distinctions of age, sex, ethnicity, and class are all related to differences in power, which accounts for differences in the degree to which groups so distinguished can make rules for others" (Becker, 1963, p. 18).

Usually, rules are the products of someone's initiative and we can think of the people who exhibit such enterprise as moral entrepreneurs. There are two kinds of moral entrepreneurs - rule creators and rule enforcer.

Sometimes, the rule creators become a crusading reformer. His focus is the content of the rules. "The existing rules do not satisfy him because there is some evil which profoundly disturbs him. He feels that nothing can be right in the world until rules are made to correct it. He operates with an absolute ethic; what he sees is truly and totally evil with no qualification'. Any means is justified to do away with it" (ibidem, p. 147-148). Frequently, he presents himself publicly as a righteous and fervent person.

Surely, it is correct to think of reformers as crusaders since they typically believe that their mission is a holy one. The prohibitionist serves as an example, as does the person who wants to suppress some sexual behaviors or the person who wants to do away with gambling. Probably, the prohibitionist policy on drugs is one of the cases that most reveals ambivalence when we consider the production of social rules. The so-called drug problem is not and never has been a police problem, except in the sense that the police are themselves the problem. It is, rather, a problem of lack of knowledge and wrong policy approach. According to Becker (2001), we should take into account the following propositions on this subject: 
1. Drug does not denote a scientific or pharmacological category. It points, rather, to a category that reflects how a society has decided to treat a substance, and it implies a classification of substances in which the term "drug" has an ambiguous status.

2. The category to which a substance is assigned affects how people who ingest that substance are treated and that, in turn, affects what the substance in question does to and for them.

3. Therefore, the solution to the problem is to redefine the phenomena involved. But this simple solution is not available because the power to define is concentrated among people whose political interest gives them no incentive to take that easy step.

\section{Drugs, moral judgment and State}

First of all, an approach about drugs should to discuss the relationship between substances and moral judgment.

Usually, we categorize the objects we ingest by the uses we put them to, the results we expect to obtain from having ingested them. Substances provide various physical and psychological states. For instance: some substances provide nourishment, and thus maintain the normal physiological functioning of our bodies; others provide the pleasures of taste and smell that we associate with wine and what we think of as well-prepared food; there are others that work to restore normal physiological functioning when our bodies do not work properly; and there also some that provide the pleasures of altered psychological states to which, in one form or another, historically all societies have found a way to gain access (Becker, 2001).

The names of the substances are important, since they suggest and legitimize action. If something is "food" or "drink," then we do not consider ingesting it an activity that the State should intervene in, other than to guarantee standards of accurate labeling of amounts and contents and healthful conditions of production and sale. If something is called a "drug," however, there are two possibilities. It can be a "medicine," in which case ingesting it is a good thing to do. The same substance, however, can be a "narcotic," in which case it should not be ingested, and should not be available for ingestion; the State properly intervenes, if necessary by use of the criminal sanction, to see that these prohibitions are enforced (ibidem). This demonstrates that the prohibitionist positions on drugs are marked by ambivalence and are based on variables of moral judgment.

So, the definitions about drugs are not just a matter of pharmacological category. Substances are frequently reclassified. Medicines become drugs, and drugs become medicines. The question cannot be settled by looking at the formula that describes the substance chemically, though this is often attempted. The crucial role in the definition process is played by the State and its power, because the State is the only actor powerful enough to exercise ultimate control on such definitions. State decides which category a substance will fall into, who may legitimately use it, how it may be manufactured and distributed, and so on. The State decides who can decide all these matters and, usually indirectly but nonetheless decisively, how they will decide them. Therefore, whether a substance is a narcotic or a medicine is decided not by the substance's pharmacology, but by how the State decides to treat it.

In fact, decisions on drugs are made in a combination of administrative and political considerations, most often understood to be a realm of "policy," official government policy. The differences between countries with respect to "drug policy" make clear how little any of these definitional processes have to do with the characteristics of the substances themselves. The differences between countries with respect to drug policy make clear how little any of these definitional processes have to do with the characteristics of the substances themselves. The national policies are not dictated by the pharmacological properties.

\section{Drug policies: the failure of prohibition}

Drug use is, and always has been, a reality in our societies. Every year, hundreds of millions of people around the world use illicit substances (United Nations Office on Drugs and Crime, 2016). For many it is about enjoyment, for some it is to relieve pain, while for others it is for traditional, cultural or religious reasons.

As the Global Commission on Drug Policy (2016) affirms, despite the widespread and non-violent nature of drug use, the predominant government response to this issue is to enact highly punitive policies that criminalize those who use and/or possess drugs, as well as other low-level actors in the drugs trade. Such policies, which were reinforced with the signing of the UN drug control treaties in the second half of the 20th century, are implemented with the misguided hope that drug use and the wider drug market can be eradicated, something that the evidence reveals is an impossibility.

In 2003, an estimated 185 million people globally aged 15-64 (4.7 percent of the world's population) had consumed an illicit drug in the previous 12 months; by 2014, this number had risen 33 percent to 247 million (5.2 percent of the world's population). The number of people who were dependent on drugs "increased disproportionally" from 27 million in 2013 to 29 million in 2014. 
At the same time, the illegal cultivation of opium poppies increased to the highest levels on record in 2014, reaching almost 320,000 hectares globally,7 while cocaine production rose 38 percent from 2013 to 2014 (Global Commission on Drug Policy, 2016, p. 11).

A lot of factors account for increases and decreases in the use and production of drugs. However, it can be observed that punitive approaches have unequivocally failed in their goal to extinguish the market. Worse, these approaches have led to devastating health and social consequences for people who use drugs, other actors in the drugs trade and wider society. On a daily basis, significant human rights abuses are carried out in the name of drug control, from the use of the death penalty and extrajudicial killings, to torture, police brutality and inhumane drug treatment programs (Gallahue \& Lines, 2015). Basically, repressive drug policies create far more harm than the drugs themselves.

Drug use crosses gender, race, class, and profession, with a significant portion of society regarding it as a normal leisure activity. The risk of imprisonment or receiving a criminal record does little to stop them from committing this offense, one which essentially causes no harm to others. It means that they do not consider themselves outsiders. This is somewhat predictable, because, as the sociology of deviance emphasizes (Becker, 1963, p. 1-2), the person who "is labeled an outsider may have a different view of the matter. He may not accept the rule by which he is being judged and may not regard those who judge him as either competent or legitimately entitled to do so. Hence, a second meaning of the term emerges: the rule-breaker may feel his judges are outsiders".

Thus, a consequence of the repressive drug policies is also the corrosion of the rule of law, as it requires that legal norms be respected. The punishment of drug possession and/or use can bring the law into disrepute. It is hard to think of another offense which causes no direct and immediate harm to others and attracts such serious penalties, while being so frequently breached.

As the Global Commission on Drug Policy (2016) points out, the widespread and persistent disregard for drug laws further calls into question the legitimacy of state actors such as the police. An example in this way is when drug laws are overwhelmingly enforced against a narrow sub-section of society, and penalties fall most heavily on the poor and those from minority communities. Such inequitable application fundamentally undermines the basic principles of the rule of law - that all in society are equally subject to the law, and that its application is consistent, fair and impartial and severely weakens the relationship between the state and its citizens (Eastwood, Shiner \& Bar, 2013; Shelby, 2004).

The resolution by states to pursue drugs punitive policies has been an expensive and willful abdication of responsibility. It allows an illicit drug market worth in excess of US $\$ 320$ billion a year to become inherently violent as gangs and organized criminal groups vie for control (Global Commission on Drug Policy, 2016). The great financial power of criminal groups has been responsible for the proliferation of corruption in the institutional spheres of various countries.

The sheer scale of financial resources which the trade hands to criminal groups provides them with the power to corrupt state officials, from the police right up to the judiciary and politicians. Indeed, the power of criminal organizations to infiltrate and corrupt state institutions and undermine the rule of law is well documented, from the endemic corruption of law enforcement and other officials in Mexico, to drug traffickers financing presidential campaigns in Guinea-Bissau (ibidem, p. 13).

On the other hand, state actors have often acted outside of the law in the name of drug control, as the barbaric actions of President Rodrigo Duterte of the Philippines can attest to. His call on the public to execute those involved with drug led to the murder of thousands of people - many of them believed to be extrajudicial killings - during his first few months in office in 2016. But, President Duterte is not alone. When Thailand launched its "war on drugs" in 2003, the result was the extrajudicial killing of almost 2,800 people (Harm Reduction International \& Human Rights Watch, 2008). In Mexico, in 2006, President Felipe Calderon announced a military crackdown on drug trafficking organizations, resulting in an estimated 160,000 homicides between 2006 and 2014, many linked to cartel violence and the militarization of drug law enforcement. Furthermore, over 280,000 people have been internally displaced in Mexican territory and at least 25,000 people have disappeared during the country's so-called drug war (Heinle, Molzahan \& Shirk, 2015).

From the point of view of public health, the consequences of the repressive drug policies have been a disaster. Criminalizing people who use drugs has fueled a "global pandemic" of HIV and hepatitis C. Globally, officially, of the 16 million people who inject drugs, approximately two-thirds are living with hepatitis $\mathrm{C}$ and at least 13 percent with HIV, with many at a heightened risk of contracting tuberculosis (Csete, 2016). Even though the hepatitis $C$ virus and tuberculosis can be cured and HIV treated, repressive drug policies, as well as the stigma and the marginalization of people who use drugs, contribute to treatment not being scaled up or reaching these populations. 
The criminalization of people who inject drugs pushes them toward risky injecting practices to avoid detection by law enforcement and acts as a barrier to accessing services, including needle and syringe programs (NSP). Additionally, many countries deny much-needed services by placing unnecessary legal restrictions on the provision of clean injecting equipment and opioid substitution therapy (OST), both of which are well-evidenced interventions that prevent the transmission of HIV and hepatitis C. By doing so, and by disproportionately focusing resources on law enforcement over public health interventions, governments are actively undermining the health of their citizens (Global Commission on Drug Policy, 2016, p. 15).

Repressive drug policies have been used as a tool of social control that causes harm not only to people involved with drugs. The whole society is affected. Drug policing is marred by high levels of racial disparity in the criminal justice system and by practices that are wholly disproportionate to the offenses involved. For instance, stop-and-search practices for drugs that exist in many countries frequently lead to people being caught up in the criminal justice system, whether or not they have drugs on them ${ }^{\text {ii }}$.

The extensive level of harm that has been caused by criminalizing people who use drugs cannot be understated. Therefore, evidence points out that the states must move toward a policy model whereby no sanctions - criminal or civil - are levied against people who use drugs.

\section{The benefits of a well-implemented drug decriminalization policy: Portugal}

Recognition of the need to respect human dignity, understand the life choices and social circumstances of others, and uphold the right to health are some of the aspects considered by the thesis of decriminalizing drug. Decriminalization means to remove of criminal penalties for drug law violations - usually possession for personal use (Hughes \& Stevens, 2010).

Decriminalizing drug possession and investing in treatment and harm reduction services can provide major benefits for public safety and health, including: increasing uptake into drug treatment; reducing criminal justice costs and redirecting resources from criminal justice to health systems; redirecting law enforcement resources to prevent serious and violent crime; diminishing unjust racial disparities in drug law enforcement and sentencing; minimizing the social exclusion of people who use drugs, and creating a climate in which they are less fearful of seeking and accessing treatment, utilizing harm reduction services and receiving HIV/AIDS service; and improving relations between law enforcement and the community.

The decriminalization of drug possession and/or use, though not commonplace worldwide, is not a particularly new approach. There have been cases of decriminalization since the 1970s, as in the Netherlands, and as a result the jurisdictions that have adopted non-punitive responses to drug possession and/or use have not experienced an increase in prevalence. A recent study (UK Government, 2014)which analyzed the drug policies of 11 countries - a mixture of those with a predominantly criminal justice approach and those that had adopted decriminalization - did not observe any obvious relationship between the toughness of a country's enforcement against drug possession and levels of drug use.

Despite there are decriminalization policies in practice across the globe, very few are well devised or implemented effectively. Consequently, they have failed to achieve positive outcomes for people who use drugs, the state and/or society. For instance, countries such as Mexico have policies where the thresholds used to distinguish possession for use from a supply offense are so small as to be meaningless. This leaves the majority of people vulnerable to being charged with drug dealing or trafficking and thus receiving a lengthy custodial sentence, despite having no involvement in those aspects of the drug trade. Even in some countries that have more realistic thresholds - like Colombia - police corruption ensures that many people who use drugs are still ensnared in the criminal justice system (Global Commission on Drug Policy, 2016).

As has emphasized the Organization of American States (2013), decriminalization of drug use needs to be considered as a core element in any public health strategy. In this way, probably Portugal is one of the main examples.

During the 1980s and 1990s, Portugal was one of the highest prevalence countries for problematic drug use, particularly heroin use. In 2001 a survey found that 0.7 percent of the population had used heroin at least once in their lives, the second highest rate in Europe after England and Wales (Open Society Foundations, 2011).

Fear of the police and being treated as a criminal dissuaded many drug users from seeking out treatment. Meanwhile, establishing syringe and needle exchange programs remained illegal. The legal system regarded drug user as a level of crime like to drug dealer. So, according to the laws based on this perspective, syringe and needle exchange programs were viewed as aiding users in committing a crime. A rise in users, a rise in patients, and a rise in social concern helped to make drugs a political issue in 1998, with prominent debates and disputes about drugs taking place in parliament, government, the media, and the streets. 
The Portuguese government responded to the rising concerns and debates by developing a rather surprising and unconventional answer. It appointed a committee of specialists - medics, sociologists, psychologists, lawyers, and social activists - and asked the committee to analyze the drug issue in Portugal and formulate recommendations that could be turned into a national strategic plan.

After eight months, the committee presented the results of its work and recommended the decriminalization of drug possession and use for both "hard" and "soft" drugs as the most effective way of limiting drug consumption and reducing the number of drug dependent persons. The committee recommended that, along with the legal changes, the government should concentrate on prevention and education, harm reduction, broadening and improving treatment programs for drug dependent persons, and activities that helped at-risk groups and current drug users maintain or restore their connections to family, work, and society (Open Society Foundations, 2011, p. 23-24).

The proposal presented by the committee was based both on humane considerations (i.e., a sick person needs help) as well as pragmatic ones (i.e., repressive measures have been ineffective at limiting consumption). Portugal's new approach resulted in the creation of Dissuasion Commissions. These replaced the criminal courts as the state's forum for responding to drug use. The commissions seek to inform people and dissuade them from drug use. They also have the power to impose civil sanctions for noncompliance and to refer consenting persons to treatment. The development of the Dissuasion Commissions was an important symbolic step that reflected a new approach to drug policy placing the commissions under Ministry of Health, rather than Ministry of Justice. The new strategy decriminalizing drug possession and use required the government to pass a suitable law, which it did in 2000. Passage of the new law and implementation of the strategy were accompanied by a series of information and education campaigns aimed at groups of potential drug users.

In this way, the strategy was comprehensive and included reasons for choosing decriminalization policy; necessary preventive and educational activities; ideas behind harm reduction policy; steps to be taken in order to improve and broaden treatment programs (financed by the state); and programs to socially reintegrate drug dependent persons.

Portuguese drug policy stipulates the exact amount of each drug that users can possess before they are treated as a drug dealer. Generally, this amount is thought to be enough for the consumption of one person over a 10-day period. In grams or pills, this means: "cannabis, 25 grams; hashish, 5 grams; cocaine, 2 grams; heroin, 1 gram; LSD or ecstasy, 10 pills" (Open Society Foundations, 2011, p. 27).

So, according to the Portuguese policy of decriminalization of drugs, the purchase, possession, and consumption of illicit drugs have been downgraded from criminal to administrative offenses. Although decriminalization differs from depenalization/legalization ${ }^{\text {iii }}$, since the purchase, possession and consumption of illicit drugs in quantities greater than those required for 10 days of consumption remain criminal offenses and carry criminal sanctions, such sanctions will usually fall short of imprisonment.

The State systematically carries out harm reduction activities. Before drug possession and use were decriminalized, the Portuguese government carried out intervention activities on a small scale based on risk reduction, but these efforts conflicted with the law and provided users with short-term aid only. The first support centers, which were not used by large numbers of people, aimed to provide users with information about treatment (although treatment was not easily available for many users). The government also helped to establish the first night shelters for users living in the streets. When the new scheme came into force in 2001, risk and harm reduction activity became systemic.

The latest available data indicate that the Portuguese Institute for Drugs and Drug Addiction finances 69 projects throughout the country, along with 30 teams of social workers who work in the streets and in centers that provide methadone for people dependent on heroin and night shelters for homeless drug users (ibidem). Street workers have several functions. For example, they talk with drug users about their history of dependence and inform them about treatment possibilities; mediate with treatment centers; and they help users to find medical and psychological support.

The last phase of drug policy is the assistance given to drug dependent individuals in their return to society. Teams taking care of social reintegration usually cooperate with treatment centers. Reintegration teams first prepare a diagnosis of the patient's condition and then, together with the patient, they draft an action plan that may include goals such as returning to higher education, work, or both. Members of the reintegration team also help the patient in finding a job or advise the patient on how to look for one (Open Society Foundations, 2011, p. 35).

The state develops a significant effort to ensure the social reintegration of people who are recovering from drug use.

While preserving the confidentiality of the individual drug user, the teams [social workers] also raise awareness in schools, businesses, and residential areas in the drug user's neighborhood. Their aim is to overcome general prejudices against drug dependent persons and so lay the ground work for patients to return to the community where they once lived and worked. 
The IDT cooperates with companies that employ drug users undergoing treatment- usually in the service sector. The IDT is able to fund a limited number of nine-month internships at these companies which can, in some cases, be extended to two-year contracts (ibidem, p. 35).

There is a significant evidence that the end of criminal sanctions for drug use and possession in Portugal has been positive. Portugal witnessed a decline in the number of criminal drug offenses from approximately 14,000 per year in 2000 to an average of 5,000-5,500 per year after decriminalization, and the number of people incarcerated for low-level drug offending fell from 44 percent of all prisoners in 1999 to 24 percent by 2013, resulting in a substantial reduction in prison overcrowding (Global Commission on Drug Policy, 2016; Hugues \& Stevens, 2010). Another relevant consequence of decriminalization is the decrease in the percentage of drug users (mostly heroin) among people infected with HIV in Portugal. This was immediately demonstrated during the early years of decriminalization. For instance, in 2000, there were 2,758 newly diagnosed cases of HIV-infected persons, of which 1,430 were drug users (52 percent). In 2008, the total number of newly diagnosed cases was 1,774, of which 352 were drug users (20 percent) (Open Society Foundations, 2011).

The decriminalization is a vital step in the right direction for drug policy reform, but it is just that - a step. As the Global Commission on Drug Policy (2016) has stated, under a decriminalized model, furthermore, society is still vulnerable to the negative effects of the illegal trade, and people who use drugs are placed at considerable risk through having to navigate the uncertainties of an unregulated market.

In order to fully mitigate the harms caused by ineffective and dangerous punitive responses to drugs, governments must ultimately regulate illicit drugs, from production through to distribution. In this way, Uruguay is an example, as it has decided to regulate the Cannabis market.

\section{Uruguayan Drug Policy: Regulated Cannabis Market}

On 20 December 2013, after the bill had passed both chambers of the Uruguayan Parliament, President José Mujica enacted Law 19.172, making Uruguay the first country in the world to legally regulate the cannabis market from seed to sale. This decision had as objective tries to reduce the potential risks and harmful effects of smoking marijuana for recreational purposes, as well as to take the cannabis market out of the hands of criminal networks and "separate the licit cannabis market from the illicit market of more harmful substances, especially the one that causes the most concern, pasta base, a crude form of cocaine base smoked throughout the region" (Transnational Institute\& Global Drug Policy Observatory, 2014, p. 56).

The Uruguayan regulation instituted three ways of access to cannabis: homegrown, commercial purchase and cannabis clubs. The Law 19.172 established, for instance, the following rules for regulation:

- Cultivation of hemp for industrial purposes (containing less than 1 per cent THC) falls under the responsibility of the Ministry of Livestock, Agriculture and Fisheries.

- Cultivation of psychoactive cannabis (containing more than 1 per cent THC) for medical purposes, scientific research or "for other purposes" requires prior authorization from the Institute for the Regulation and Control of Cannabis.

- Cultivation of cannabis for personal consumption or shared use at home is permitted up to six plants with a maximum harvest of 480 grams per year.

- Membership clubs with a minimum of 15 and a maximum of 45 members, operating under control of the IRCCA, are allowed to cultivate up to 99 cannabis plants with an annual harvest proportional to the number of members and conforming to the established quantity for non-medical use.

- IRCCA licenses pharmacies to sell psychoactive cannabis for therapeutic purposes on the basis of medical prescription, and for non-medical use up to a maximum of 40 grams per registered adult per month.

- Any plantation operating without prior authorization shall be destroyed upon the order of a judge.

Institute for the Regulation and Control of Cannabis (IRCCA) was designed with a special emphasis on encouraging cooperation across a variety of other state entities with responsibilities relevant to cannabis regulation. While the institute follows the policy directives of the National Drug Council (JND), it is also formally under the umbrella of the Ministry of Public Health. In addition to the IRCCA president, the board of the institute includes representatives of the Ministries of Public Health; Social Development; and Livestock, Agriculture, and Fishing. The text of the law gives the IRCCA a broad mandate to maintain anonymous registries of those intending to purchase cannabis, as well as all club members and home growers. "In implementing Uruguay's law, authorities have placed a clear emphasis on law enforcement aimed at non-compliant clubs and home grows, hoping to prevent them from fueling a black market" (Hudak et. al., 2018, p.12).The IRCA is very active in this regard. 
On the other hand, the text of the cannabis regulation law establishes a strong connection with education in order to develop prevention campaigns. So, since December 2013, the National Drug Board (JND) has carried out one major abuse prevention campaign involving cannabis, which is also designed to target the abuse of alcohol and other substances. The campaign is titled "Consuming any drug has risks". Its objectives are 1.) to encourage adult consumers of both cannabis and alcohol to educate themselves about responsible consumption and the health risks associated with ingesting mind-altering substances, and 2.) foster a culture of "zero consumption" among pregnant women, drivers, and youth under the age of 18. To this end, the National Drug Board has promoted the campaign on social media and paid for radio and television spots which have played on public media outlets, as well as for limited billboard space at bus stops and on public transportation in major cities.

In short, it is possible to say that Uruguayan policy of regulation of the cannabis market has two keys. The first is the public health. There was a sustained increase in consumption under prohibition. The market was entirely under the control of organized criminal groups. The new reality with regulation is changing that. Cannabis products will safer because the producers are licensed by the government under strict standards, and cannabis is sold through pharmacies. There is control of the potency and price, as well as health information on the packaging and who can access the market. The second element is about community safety and respecting human rights - curtailing the threat of organized criminal groups and the violence associated with the illegal drug trade. It's affirmed that the rights of people who use drugs should be considered and respected. In this way, the philosophy of Uruguayan drug policy assumes that human rights obligations take precedence over drug control efforts. It advocates that security will improve if there is respect for human rights, and if the region's governments also address this issue together.

However, the Uruguayan drug policy has faced some adversities. One of them is the opposite of the international prohibitionist system of drug control. For example, the International Narcotics Control Board (INCB) has rejected the Uruguayan policy. As said by Board, such policy is contrary to the provisions of the international drug control conventions, particularly to the measures set out in article 4, paragraph (c), of the 1961 Convention as amended, according to which states parties are obliged to limit exclusively to medical and scientific purposes the production, manufacture, export, import, distribution of, trade in, use and possession of drugs (International Narcotics Control Board, 2017).

In opting for regulation notwithstanding such criticisms, Uruguay has sought to side step the question of drug treaty non-compliance by placing its new law in the context of the country's adherence to its more foundational obligations under international law. Uruguayan authorities have specifically argued that the creation of a regulated market for adult use of cannabis is driven by health and security imperatives and is therefore an issue of human rights. As such, officials point to wider UN human rights obligations that need to be respected, specifically appealing to the precedence of human rights principles over drug control obligations within the UN system as a whole (Hudak et. al., 2018).

Fundamentally, the thesis in defense of regulating the cannabis market is based on the assumption that, in the conflict between human rights obligations and drug control requirements, Uruguay gives priority to its human rights obligations.

\section{Conclusion}

As Becker (1963) has said, scientists do not ordinarily question the label "deviant" when it is applied to particular acts or people but rather take It as given. In so doing, they accept the values of the group making the judgment. It is easily observable that different groups judge different things to be deviant. This should alert us to the possibility that the person making the judgment of deviance, the process by which that judgment is arrived at, and the situation in which it is made may all be intimately involved in the phenomenon of deviance. To the degree that the common-sense view of deviance and the scientific theories that begin with its premises assume that acts that break rules are inherently deviant and thus take for granted the situations and processes of judgment, they may leave out an important variable. If scientists ignore the variable character of the process of judgment, they may by that omission limit the kinds of theories that can be developed and the kind of understanding that can be achieved.

So, that is a fundamental perspective to be adopted in the debate on drug policies. It helps to deconstruct myths and stereotypes created by the prohibitionist approach, which have produced countless problems in several countries. Such deconstruction is a vital step to national reforms that regulates illicit drugs, from production through to distribution. International treaties cannot block countries from fulfilling their commitments to their citizens. There is no international convention that frees states from their obligations towards their populations, to protect their lives, their health, their dignity, and to guarantee equal rights for all without discrimination. Human rights come first.

\section{Sponsoring information}

National Council for Scientific and Technological Development (CNPQ)/Brazil 


\section{References}

Becker, H. S. (1963). Outsiders: studies in sociology of deviance. New York: The Free Press.

Becker, H. S. (1972). Labeling theory reconsidered, in Deviance and Social Control, edited by Paul Rock and Mary MacIntosh. London: Tavistock.

Becker, H. S. (2001). Les drogues: que sont-elles?, in Howard S. Becker, ed., Qu'est-ce qu'une drogue?, Anglet: Atlantica, pp. 11-20.

Csete, J. et al. (2016), Public health and international drug policy, The Lancet Commissions, The Lancet 387 (10026), p. $1427-1480$.

Eastwood, N., Shiner, M. \& Bear, D. (2013), The Numbers in Black and White: Ethnic Disparities in the Policing and Prosecution of Drug offenses in England and Wales, in Release \& LSE, London.

European Monitoring Centre for Drugs and Drug Addiction (2005), Illicit Drug Use in the EU: Legislative Approaches, Lisbon: EMCDDA.

Gallahue, P. \& Lines, R. (2015), The Death Penalty for Drug Offences: Global Overview2015, London: International Harm Reduction Association.

Global Drug Policy Observatory (2014).

Global Commission on Drug Policy (2016). Report of the Global Commission on Drug Policy - Advancing drug policy reform: A new approach to decriminalization,

http://www.globalcommissionondrugs.org/wpcontent/uploads/2016/11/GCDP-Report-2016-ENGLISH.pdf, (accessed September 04, 2018).

Harm Reduction International \& Human Rights Watch (2008), Thailand's 'war on drugs', HRW: New York, https://www.hrw.org/ news/2008/03/12/thailands-war-drugs (accessed September 05, 2018).

Heinle, K., Molzahan, C. \& Shirk, D. (2015), Drug Violence in Mexico: Data and Analysis Through 2014, Justice in Mexico Project, San Diego: University of San Diego.

Hudak, J., Ramsey, G., Walsh, J. (2018). Uruguay's cannabis law: Pioneering a new paradigm. [pdf] Washington D.C.: WOLA. Available at: https://www.wola.org/wp-content/ uploads/2018/03/gs_032118_Uruguayscannabis-law_FINAL.pdf [Accessed 18 July 2018].

Hughes, C. E. \& Stevens, Alex, What Can We Learn from the Portuguese Decriminalization of Illicit Drugs?, British Journal of Criminology 50, no. 6 (2010): 999.

International Narcotics Control Board (2017). Report of the International Narcotics Control Board for 2016. New York: United Nations.

Open Society Foundations (2011). Política da droga em Portugal: os benefícios da descriminalização do consumo de drogas. Budapest: Createch Ltd.

Organization of American States (OAS) (2013), The Drug Problem in the Americas: Analytical Report, OAS: General Secretariat, 103.

Shelby, T. (2004), Race and Ethnicity, Race and Social Justice: Rawlsian Considerations, in Fordham Law Review 72 (5): 1705.

Transnational Institute \& Global Drug Policy Observatory (2014). The rise and decline of control cannabis system and options for reform. Amsterdam: Jubels.

UK Government (2014), Drugs: International Comparators. London: UK Home Office

United Nations Office on Drugs and Crime (UNODC) (2016), World Drug Report 2016, Vienna: United Nations.

World Health Organization (2014), Guidelines for the screening, care and treatment of persons with hepatitis C infection. Geneva: WHO.

\footnotetext{
${ }^{\mathrm{i}}$ While the State can be, and often is, arbitrary, it more often tries to produce a believable rationale for its actions, and most often tries to do this through science or through a combination of science and morality (Becker, 2001).

ii The situation in United Kingdom is an illustrative example. According to Global Commission on Drug Policy (2016), 60 percent of all police searches are for drugs, 74 predominantly for "low level street possession." In the vast majority of cases no drugs are found. Worse, black people are six times more likely to be stopped and searched for drugs than white people, and Asians twice as likely, despite the fact that drug consumption is higher among white people. "This kind of disparity is replicated around the world, with minority and economically marginalized communities often targeted. Police practices used for detecting drug possession often include repeated harassment of certain communities, strip searches of individuals and forcible entries of homes. They also contribute to the breakdown of the relationship between communities and states, as law enforcement is viewed as lacking legitimacy" (ibidem, p. 17).

iii Under the European Monitoring Centre for Drugs and Drug Addiction (EMCDDA) definition, "decriminalization comprises removal of a conduct or activity from the sphere of criminal law. Prohibition remains the rule, but sanctions for use (and its preparatory acts) no longer fall within the framework of the criminal law. [By contrast], 'depenalization' means relation of the penal sanction provided for by law. In the case of drugs, and cannabis in particular, depenalization generally signifies the elimination of custodial penalties" (European Monitoring Centre for Drugs and Drug Addiction, 2005, p. 4).
} 